\title{
Method of Determining the Location of the Sexual Neurovascular Bundle (Internal Pudendal Artery, Internal Pudendal Vein and Pudendal Nerve)
}

\author{
Método para Determinar la Ubicación del Haz Neurovascular Sexual \\ (Vena y Arteria Pudenda Interna y Nervio Pudendo)
}

Zhandarov K. A.; Dydykin S. S.; Vasil'ev Yu. L.; Nelipa M. V.; Kytko O. V. \& Mirontsev A.V.

ZHANDAROV, K. A.; DYDYKIN, S. S.;VASIL'EV YU, L.; NELIPA, M. V.; KYTKO, O. V. \& MIRONTSEV, A. V. Method of determining the location of the sexual neurovascular bundle (internal pudendal artery, internal pudendal vein and pudendal nerve). Int. $J$. Morphol., 38(4):1142-1147, 2020.

SUMMARY: Disorders in the course of the neurovascular bed of the sexual neurovascular bundle (NVB) entail problems of gynecological, andrological and urological nature, for example, the state of impotence in men. The aim of the study was to establish a method to determine a projection. The Arteria pudenda interna, Vena pudenda interna and Nervus pudendus (sexual neurovascular bundle or NVB) from the infrapiriform foramen to the Alcock's canal (pudendal canal) in which the pudendal neurovascular bundle runs. Topographic and anatomical study was performed on 15 corpses without organ complex (remote shore): 9-from men and 6-women, aged 36 to 74 years. Each object of study (corpse) included 2 pairs of sexual NVB, a total of 30 investigated. The information obtained on the projection branches of the pudendal nerve, and pudendal internal artery and pudendal internal vein from infrapiriform foramen to the entrance of the pudendal canal. A method for determining the projection of sexual NVB in the gluteal region was developed. The projection of Arteria pudenda interna, Vena pudenda interna and Nervus pudendus from the infrapiriform foramen in the gluteal region and to the entrance of the pudendal canal is determined. The morphometric data necessary for the mathematical equation developed by us for the calculation of the boundaries of the projection of the desired plane in the course of the sexual NVB are obtained. Using these data in the method of mathematical calculation developed by us using the formula $C^{\prime} c^{\prime}=0,2679 \times(A ' G-A D+3)$, we determined the projection of the figure, in the form of a trapezoid, in the center of which the projection of the sexual NVB is determined.A method for determining the projection of the sexual neurovascular bundle in the gluteal region for diagnosis and therapeutic effects on sexual NPS was developed.

KEY WORDS: Sexual neurovascular bundle; Anatomical study; Pudendal canal.

\section{INTRODUCTION}

Disorders in the course of the neurovascular bed of the sexual neurovascular bundle (NVB) (Arteria pudenda interna, Vena pudenda interna and Nervus pudendus) entail problems of gynecological, andrological and urological nature, for example, the state of impotence in men. This is also true for traumatic injuries, and when sexual NVB can be squeezed by tumors, with the degeneration of the genital nerve into neurinoma. Knowledge of the topography of pudendal nerve is very important for the performance of its blockade with the goal of pain relief neuralgia (Vancaillie et al., 2012). In all these cases, the treatment of the emerging tunnel syndrome can be both medical and surgical. Sexual nerve neuralgia can be diagnosed by 5 clinical signs of Nantes, its prevalence covers about $1 \%$ in the population (Labat et al., 2007). Myofascial syndrome (piriformis syndrome) is a common cause of non-vertebral radiculopathy in the case of compression of the sciatic nerve between the altered piriformis muscle and the sacroiliac ligament, as well as the passage of the nerve through the muscle itself (piriformis muscle syndrome and tunnel compression of the genital nerve) (Siddiq et al., 2014).

In the projection of the infrapiriform foramen, all the nerves are in close contact with each other, in addition, the compression of its structures is likely in several locations: in the perineum - in the pudendal canal, in the terminal branches under the lower surface of the pubic bones, in the gluteal region between the sacroiliac and sacroiliac ligaments (Robert et al., 1998). The latter circumstance is of particular interest, since there the elements of the beam are fixed. 
Despite the existing methods of diagnosis (magnetic resonance neurography, ultrasound diagnostics), the determination of the position of the branches or section of the sexual neurovascular bundle often raises questions due to the variability of anatomy, the difficulty of determining the branches (in this area there is a large number of layered arteries of similar caliber passing in this area) (Rojas-Gómez et al., 2017), especially in the absence of a number of medical institutions and private practices (manual therapists) as the necessary trained specialists of radiation diagnosis, and expensive equipment. For training of specialists presents the method of determining the sex of NVB described by Corning in the section "finding the nerves and vessels of the region glutea" his leadership (Corning, 1949).

When using this method, is a specialist with a strong desire, difficult to determine in a patient the whole of the projection beam, as recommended anatomical elements and landmarks can be palpated only the ischial tuberosity. This method is based on the projection of the lower gluteal artery and only indirectly reports a possible finding of the genital artery in a narrow area of the region.

During the topographic and anatomical study of the gluteal region, we developed a method for determining the projection of the sexual neurovascular bundle in the gluteal region, using external landmarks and a mathematical equation. For this purpose, the necessary data for the calculation of the boundaries of the projection of the plane, and the center of this figure determined the projection of the sexual NVB.

Our study allows us to understand the complex anatomy of sexual NVB and enables students and practitioners to easily determine its projection, thereby reducing the likelihood of errors in the treatment of patients with pathology of sexual NVB.

On the basis of topographic and anatomical, morphometric studies we developed a method for determining the projection of internal pudendal artery, internal pudendal vein and and pudendal nerve (sexual neurovascular bundle) from the infrapiriform foramen to the Alcock (the pudendal) canal.

\section{Goal of the research were:}

1. To study the topographic and anatomical characteristics of the musculoskeletal structures and holes in the course of the sexual neurovascular bundle in the gluteal region to the pudendal canal. 2. Obtain morphometric data to determine the boundaries of the projection plane in the gluteal region within which the sexual NVB.

3. To develop a mathematical method for determining the position of the beam by a specially derived formula, taking into account the data obtained.

\section{MATERIAL AND METHOD}

The study was performed using a binocular magnifier with an increase of 6-10 times. Measurements were carried out using a Vernier caliper with a Vernier scale with accuracy and a depth gauge with an accuracy of $0.1 \mathrm{~mm}$. Photography was carried out on a digital camera "Olympus" with the possibility of increasing by 10 times.

Topographic and anatomical study was performed on 15 corpses without organ complex (remote shore): 9-from men and 6-women, aged 36 to 74 years. Each object of study (corpse) included 2 pairs of sexual NVB, a total of 30 investigated. All bodies were identified, age, gender, and cause of death were established.

Layer-by-layer dissection was performed at the position of the body on the abdomen in the gluteal regions. In the position of the body on the abdomen, the skin and underlying tissues of the gluteal region were removed, producing a layered incision: from the top - along the crest of the iliac bones, from the outside - from the anterior upper iliac spine vertically down and from the side of the greater trochanter of the femur to the gluteal fold. In the area of the gluteal fold, the incision went along it with the transition to the femoral-perineal fold, from the inside - along the median line along the sacrum and coccyx to the line of the previous incision.

Further, layer-by-layer preparation with removal of muscle, fat and connective tissue along the vessels and nerve was performed. The preparation was performed at 6-8 times magnification, measured with a Vernier caliper.

Measurements were carried out to obtain the average data, which allowed us to build the boundaries of the projection plane in the gluteal region within which the sexual NVB passes.

Morphometry in the gluteal region included the determination of the distance from the median line of the body (in the center of the sacrum) to the infrapiriform foramen to determine the size of the area of passage of sexual NVB under it. Was recorded the distance from the location of attachment of the Sacro-tuberositas ligament (the lateral edge of the sacrum) at its upper edge to infrapiriform foramen and from the location of attachment of the Sacrotuberositas ligament (the lateral edge of the sacrum) at its upper edge to point of buttock. Also, the distance from the place of attachment of the sacroiliac ligament (lateral edge of the sacrum) along its lower edge to the tuberosity of the ischium was fixed. We determined the width of the sacroiliac 
ligament in its largest place - that is, the distance from the upper to the lower edge of the sacroiliac ligament at the place of its attachment (lateral edge of the sacrum). To construct the projection of the passage of the sexual NVB under the ligament, the distance from the place of attachment of the sacroiliac ligament (lateral edge of the sacrum) along its upper edge to the inlet to the genital canal and from the tuberosity of the ischium to the inlet to the genital canal was determined.

To construct the boundaries of the plane projection in the gluteal region, within which the sexual NVB passes, the distance from the median line to the tuberosity of the ischium and the distance from the projection line of the tuberosity of the ischium to the horizontal line between the midline of the body and the greater trochanter were measured.

We measured the maximum possible cut, which is gender of NVB to the medium line from point of buttock and the maximum possible interval from the medial edge of infrapiriform foramen to the sciatic nerve at the exit from infrapiriform foramen.

The obtained data were used in the method developed by us to determine the projection of the sexual NVB, for which the construction of the plane of projection of the sexual NVB on the body was performed as follows:

Using a ruler, the distance from the tuberosity of the ischium (point $\mathrm{D}$ ) to point $\mathrm{A}$ on the midline of the body (A$\mathrm{A}^{\prime}-\mathrm{A}^{\prime \prime}$ ) along the horizontal line was measured.

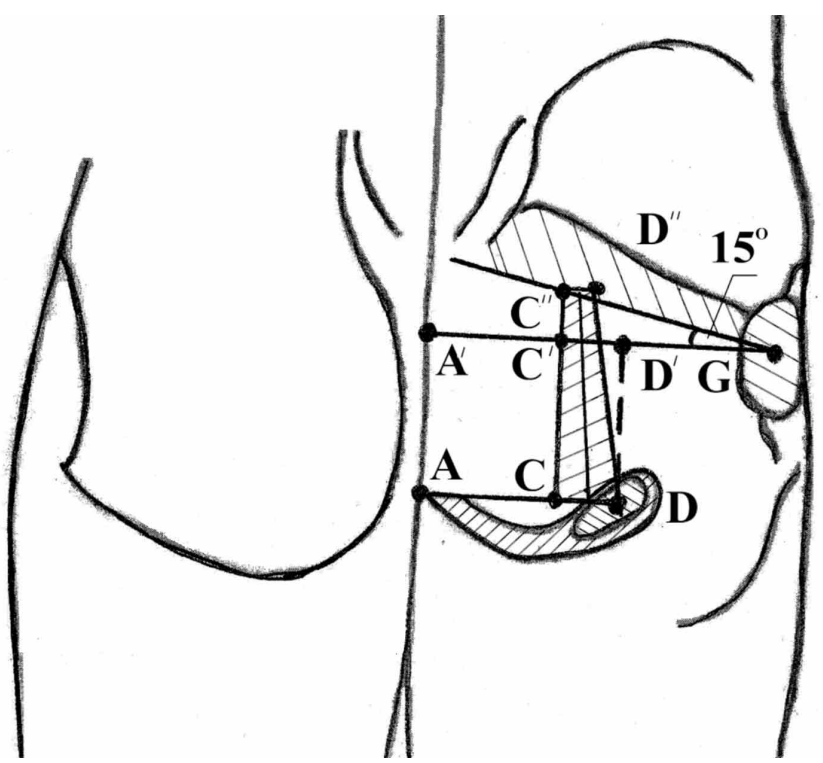

Fig.1 Scheme of construction of the projection of sexual neurovascular bundle (NVB) on the plane.
Then the distance from the greater trochanter (point $\mathrm{G})$ to the point $\mathrm{A}^{\prime}$ on the midline of the body (A-A'-A") along the horizontal line was measured.

A vertical straight line was drawn up from point D. At the intersection with the horizontal line from the greater trochanter - $G$ to the midline of the body, the point D' was determined. Then the length of this segment was measured.

At a distance of $3 \mathrm{~cm}$ along a horizontal line from point $\mathrm{D}$, passing to the midline of the body, marked point $\mathrm{C}$, received a segment $\mathrm{CD}$.

Next, a vertical line was drawn up from point $C$ and at the intersection with the horizontal line from point $\mathrm{G}$ marked point $C^{\prime}$. The length of the segment $C^{\prime}$ ' is equal to the segment DD', i.e. $5 \mathrm{~cm}$.

Then the length of the segment C' $-C^{\prime}$ was calculated.

From the presented scheme (Fig. 1), it can be seen that $C^{\prime}-C^{\prime}$ is a leg of a right triangle, and therefore the length of this segment can be calculated by the following formula: Tangent angle $15^{\circ}=\mathrm{C}^{\prime} \mathrm{C}^{\prime \prime} /\left(\mathrm{A}^{\prime} \mathrm{G}-\mathrm{AD}+3\right)$

From the theory of mathematical calculations it is known that the tangent angle of $15^{\circ}=0.2679$. Hence, $C^{\prime} C^{\prime \prime}$ $=0.2679\left(\mathrm{~A}^{\prime} \mathrm{G}-\mathrm{AD}+3\right)$. To determine the length of the segment CC", the distances of the segments CC' and C'C" are summed:CC" $=\mathrm{CC}+\mathrm{C}{ }^{\prime} \mathrm{C}^{\prime}$.

Then using a ruler distance C'C" vertically up from the point $\mathrm{C}$ was measured, then $1 \mathrm{~cm}$ from the point $\mathrm{C}^{\text {' }}$ wasmeasured on a horizontal line and put the point $\mathrm{D}^{\prime}$ connecting this point with the point $\mathrm{D}$, received the location of the desired projection, namely the trapezium C-C'-D'-D in the gluteal region.

Then we carried out at the center of this figure the vertical line of projection of the sexual sort.

\section{RESULTS}

Topographic and anatomical study was carried out on the basis of the pathoanatomical Department of NIISP im. N. In. Sklifosovsky (head. Ph. D. Kanibalotsky AA) and at the Department of operative surgery and topographic anatomy of the First MSMU. I. M. Sechenov. The work was taken into account by the local ethics Committee, Protocol No. 06-12, dated 14.04.2018. The work was carried out12.01.1996 8-FZ (ed. from 03.07.2016, Rev. from 
19.12.2016) "On burial and funeral business" (from izm. and DOP., entry. in force from 01.01.2017).

Topographic and anatomical study of 30 sexual NVB on 15 corpses aged 36-74 years, 9 male and 6 female. The main cause of death of coronary artery disease, acute cardiovascular insufficiency. Autopsy and an accompanying medical history of symptoms of disease of the pelvis, such as cancer, fractures of the pelvis or historical trauma of the pelvis have been identified.

From the ischial tuberosity at an angle of $45^{\circ}$ to the midline, the sacroiliac ligament was determined. We traced the upper and lower edges of the sacroiliac ligament. The width of the sacroiliac ligament between them varies from 1 to $2.5 \mathrm{~cm}$ (Fig. 2) and actually corresponds to the length of

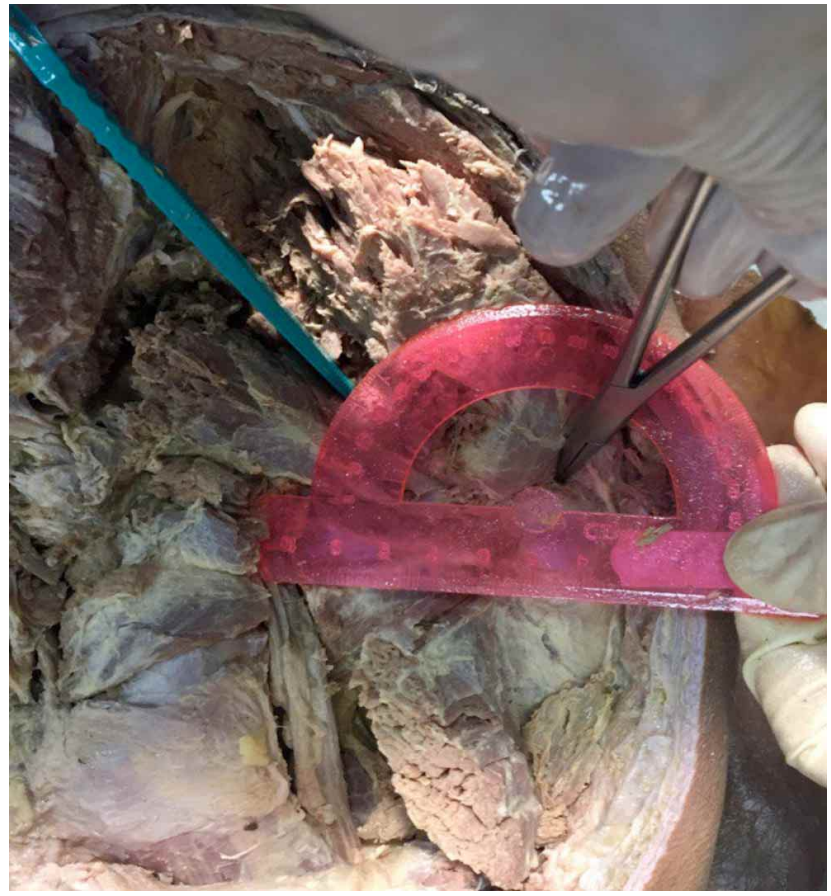

Fig. 2. Morphometric study of the internal sexual NVB. the II segment of the channel beginning with the inlet holes at the lower edge of the sacroiliac ligament.

To build the projection of the passing of the sexual NVB from the piriformis muscle in the projection of the two segments of the vestibule of the pudendal canal morphological measurement of sex 30 channels in 15 anatomical sites. The results of our measurements are presented in Table I.

The maximum medial deviation of the location of the NVB from a sexual point of buttock to $3 \mathrm{~cm}$, the maximum possible interval from the medial edge of infrapiriform foramen to the sciatic nerve at the exit from infrapiriform foramen of the hole is $1 \mathrm{~cm}$. Based on the data obtained, we have developed a method for determining the external projection of the internal sexual NPS.

As an example, we present the construction of the plane of projection of the sexual NVB, on the male body N (Fig. 1).

Using the ruler, the distance from the ishial tuberosity (point $\mathrm{D}$ ) to the midline of the body (point A) horizontally was measured. The length of the segment $\mathrm{AD}=8.5 \mathrm{~cm}$ is determined.

The distance from the greater trochanter (point $\mathrm{G}$ ) to the midline of the body (point A') horizontally was measured. The length of the segment was $A^{\prime} G=14,6 \mathrm{~cm}$.

A vertical straight line is drawn up from point $\mathrm{D}$. At the intersection with the horizontal line passing through the greater trochanter $-A^{\prime} G$ - to the middle line of the body, the point D' was set.

The length of the resulting segment DD ' $=5 \mathrm{~cm}$.

At a distance of $3 \mathrm{~cm}$ for the horizontal line from point $\mathrm{D}$ that passes to the midline of the body, marked by point $\mathrm{C}$. the resulting segment $\mathrm{CD}=3 \mathrm{~cm}$.

Table I. Initial morphometric data.

\begin{tabular}{|c|c|c|}
\hline Nameofindicator & $\min$ & $\max$ \\
\hline Distance from the midline toinfrapiriform foramen holes $(\mathrm{cm})$ & 4.6 & 6.0 \\
\hline The maximum medial deviation of the location of the NVB of the penis from the ischial tuberosity $(\mathrm{cm})$ & & 3.0 \\
\hline $\begin{array}{l}\text { The maximum possible interval from the medial edge of the infrapiriform foramen to the sciatic nerve at the exit } \\
\text { of the infrapiriform foramen }(\mathrm{cm})\end{array}$ & & 1.0 \\
\hline $\begin{array}{l}\text { The distance from the ischial tuberosity to the horizontal line connecting the midline of the body with a } \\
\text { ectotrochanter }\end{array}$ & 3.6 & 6.0 \\
\hline $\begin{array}{l}\text { The average distance from the lower edge of the piriformis muscle at the exit of the pudendal nerve to the upper } \\
\text { edge of the Sacro-bogorny ligament (Segment threshold) }(\mathrm{cm})\end{array}$ & 0.4 & 0.6 \\
\hline $\begin{array}{l}\text { Distance from the upper to the lower edge of the sacroiliac ligament in the projection of the sexual bundle (II } \\
\text { segment of the vestibule) }(\mathrm{cm})\end{array}$ & 1.0 & 2.5 \\
\hline Distance from the midline of the body to the ischial tuberosity $(\mathrm{cm})$ & 6.0 & 8.5 \\
\hline Distance from the buttock to the greater trochanter $(\mathrm{cm})$ & 6.0 & 8.0 \\
\hline
\end{tabular}


ZHANDAROV, K. A.; DYDYKIN, S. S.;VASIL'EV YU, L.; NELIPA, M. V.; KYTKO, O. V. \& MIRONTSEV, A. V. Method of determining the location of the sexual neurovascular bundle (internal pudendal artery, internal pudendal vein and pudendal nerve). Int. J. Morphol., 38(4):1142-1147, 2020.

A vertical line is drawn up from point $\mathrm{C}$ and at the intersection with the horizontal line a'g marked point C'. Since the length of the segment $\mathrm{CC}^{\prime}$ ' is equal to the segment $\mathrm{DD}^{\prime}, \mathrm{CC}^{\prime}=5 \mathrm{~cm}$.

At the intersection of the continuation of the vertical line SS' and the lower edge of the projection of the piriformis muscle marked point C'.

Now, to determine the location of the projection of the area within which the sexual NVB passes, the length of the segment C'c" is determined by the formula:

$$
\begin{aligned}
& \mathrm{CC}^{\prime}=0,2679 \times(\mathrm{AG}-\mathrm{AD}+3)=0,2679 \times(14,6-8,5+3) \\
& =2.44 \mathrm{~cm}
\end{aligned}
$$

To determine the length of the segment $\mathrm{CC}^{\prime}$, the distances of the segments $\mathrm{Cc}^{\prime}$ : $\mathrm{CC}^{\prime}=\mathrm{CC}^{\prime}+\mathrm{CC}^{\prime}=5 \mathrm{~cm}+2.44 \mathrm{~cm}=7.44$ $\mathrm{cm}$ were summed.

Then measured $7.44 \mathrm{~cm}$ vertically up from point $\mathrm{C}$ (marked point C'). Then measured $1 \mathrm{~cm}$ from point $C$ ' on a horizontal line and set the point D". As a result, we got the location of the desired projection, namely the trapezoid CC"-D"-D in the gluteal region. The vertical line of projection of sexual NVB is carried out on the center of this figure.

In the subsequent topographic and anatomical study by layer-by-layer tissue preparation and morphometry with photography, our calculations are confirmed (Fig. 2).

This method can be used to determine the projection of the internal sexual NVB on the body. As well as for manual therapy with the effect on the components of sexual $\mathrm{NVB}$, determining the projection of the surgical incision for access to sexual NVB, for the purpose of blockade of the internal genital nerve, for the diagnosis of patients with neuropathy, neurinoma of the internal genital nerve, as well as vascular pathologies of the internal genital NVB. The method makes it possible to determine the projection without special equipment by practitioners and students, thereby reducing the likelihood of errors in the treatment of patients with pathology of internal sexual NVB.

\section{DISCUSSION}

As is known, the genital nerve is divided into the intra-phase part and the extra-phase part and is the caudal part of the sacral plexus S2-S3-S4. In this study, we analyzed in detail the course of the extra-phase part of the genital nerve in the gluteal region, and in the space under the sacroiliac ligament before entering the splitting of the own fascia of the internal obturator muscle - the pudendal canal.

The data obtained as a result of studies at 15 sites of 30 internal genital NVB confirm the observations of other authors (Mahakkanukrauh et al., 2005; Alsaid et al., 2011) that the extra-phase branch of the genital nerve and the internal genital artery (the final branch of the internal iliac artery) take their joint origin in the abdominal floor of the small pelvis, where the anterior branch of the internal iliac artery passes between the trunks of the sacral plexus ending up in the pre-sacral fascia (Waldeyer fascia) (GarcíaArmengol, et al., 2008). Leaving under the medial part of infrapiriform foramen in the gluteal region, the nerve and artery are very close together and in parallel. It should be noted that the lateral beam from the penis out of the hole (infrapiriform foramen ) go back cutaneous nerve of the thigh (posterior femoral cutaneous nerve), the artery accompanying the sciatic nerve (artery to sciatic nerve), sciatic nerve (sciatic nerve), and the inferior gluteal neurovascular bundle (internal pudendal artery, internal pudendal vein and pudendal nerve).

Such a close of anatomical syntopic elements complicates the differential diagnosis of various pathologies. In particular, the existence of common epineurium at several nerve trunks implies the occurrence of reflected pain, such as piriformis syndrome. According to some authors, myofascial pain syndrome (piriformis syndrome) is a common cause of radiculopathy in sciatic nerve compression between the altered piriformis muscle and sacroiliac ligament (Siddiq et al.). Found the description of cases reflected the pain associated with the projections of one nerve trunk adjacent to a nerve, in close apposition (in the beam) infrapiriform foramen (Hopayian et al., 2010), and this is understandable, in its course of the nerves can communicate with nearby nerves with their nerve fibers, and further interacted with each other to form a plexus (plexus). Nerve plexus are formed in connection with the differentiation of tissues and organs and are complex connections, where there is an exchange between nerve fibers, bundles, nerves. Based on this, it is possible to consider pear muscle syndromes, tunnel compression of the genital nerve, as reflected pain, for example, in sciatica, and the possibility of pain in the course of the sciatic nerve as a result of stenosis of the genital nerve. These problems are often faced by clinicians: neurologists, vertebrologists, urologists and gynecologists, and according to experts, one of the important and often overlooked causes is the neurogenic cause of pelvic pain, namely the neuralgia of the genital nerve. It is possible due to the fact that in the publications of specialists on this topic there is practically no significant information on the study of variant anatomy (Moszkowicz et al., 2012). 
To develop a method of diagnosis and improve operational access, it is necessary to have a clear anatomical understanding of the zone of passage of sexual NPS and its direction in the tissues.

Accuracy in finding the topographic and anatomical location of the NVB opens new horizons for the development of surgical approaches and studies of various pathologies of the nerves in the perineum and pelvis.

In our study, the morphometry of 3 parameters necessary to determine the projection of the sacroiliac ligament in the gluteal region and 4 parameters to determine the projection of the internal sexual NVB in the gluteal region was carried out. Experimentally, using the construction of a mathematical equation, the results of the boundaries of the projection of the plane within which the sexual NVB passes in the gluteal region are determined and verified.

As a result, a method was developed for determining the projection of the internal sexual NVB with an original mathematical equation using the parameters and external landmarks obtained. Previously, there was no objective method for determining the projection of sexual NVB (Alsaid et al.).

\section{CONCLUSION}

In our work we proposed a method of topographic and anatomical determination of the passage of sexual NPS, which serves as the basis for the development of new surgical approaches and non-invasive methods of its treatment.

ZHANDAROV, K. A.; DYDYKIN, S. S.;VASIL'EV YU, L.; NELIPA, M. V.; KYTKO, O. V. \& MIRONTSEV, A. V. Método para determinar la ubicación del haz neurovascular sexual (arteria pudenda interna, vena pudenda interna y nervio pudendo). Int. J. Morphol., 38(4):1142-1147, 2020.

RESUMEN: Los trastornos en el curso de las estructuras del haz neurovascular sexual conllevan problemas de naturaleza ginecológica, andrológica y urológica, por ejemplo, el estado de impotencia en los hombres. El objetivo de este estudio fue establecer un método para determinar una proyección de los vasos pudendos internos y el nervio pudendo (haz neurovascular sexual o HNV) desde el foramen infrapiriforme hasta el canal de Alcock (canal pudendo). Se realizó un estudio topográfico y anatómico en 15 cadáveres: 9 hombres y 6 mujeres, entre 36 y 74 años. Se analizaron 30 muestras, cada cadáver incluyó 2 pares de HNV sexuales. Se obtuvo información sobre las ramas de proyección de la arteria, y vena pudenda interna y del nervio pudendo, desde el foramen infrapiriforme hasta la entrada al canal pudendo. Se desarrolló un método para determinar la proyección de NVB sexual en la región glútea. La proyección de la vena pudenda interna y del nervio pudendo se determinó desde el foramen infrapiriformis en la región glútea, hasta la entrada del canal pudendo. Se obtuvieron datos morfométricos necesarios para la ecuación matemática y obtener el cálculo de los límites de la proyección del plano deseado en el curso de la HNV sexual. Usando estos datos se utilizó la fórmula $C^{\prime} \mathrm{c} '=0,2679 \mathrm{x}$ $\left(A^{\prime} \mathrm{G}-\mathrm{AD}+3\right)$, y se realizó la proyección de la figura, en forma de trapecio, en el centro del cual se determinó la proyección de la HNV sexual. Se desarrolló un método para la proyección del haz neurovascular sexual en la región glútea, en el diagnóstico y los efectos terapéuticos sobre el NPS sexual.

PALABRAS CLAVE: Haz neurovascular sexual; Estudio anatómico; Canal pudendo.

\section{REFERENCES}

Alsaid, B.; Moszkowicz, D.; Peschaud, F.; Bessede, T.; Zaitouna, M.; Karam, I.; Droupy, S. \& Benoit, G. Autonomic-somatic communications in the human pelvis: computer-assisted anatomic dissection in male and female fetuses. J. Anat., 219(5):565-73, 2011.

Corning, H. K. Lehrbuch der Topographischen Anatomie. München, J.F. Bergmann-Verlag, 1949. https://doi.org/10.1007/978-3-642-53305-1

García-Armengol, J.; García-Botello, S.; Martinez-Soriano, F.; Roig, J. V. \& Lledó, S. Review of the anatomic concepts in relation to the retrorectal space and endopelvic fascia: Waldeyer's fascia and the rectosacral fascia. Colorectal Dis., 10(3):298-302, 2008.

Hopayian, K.; Song, F.; Riera, R. \& Sambandan, S. The clinical features of the piriformis syndrome: a systematic review. Eur. Spine J., 19(12):2095$109,2010$.

Mahakkanukrauh, P.; Surin, P. \& Vaidhayakarn, P. Anatomical study of the pudendal nerve adjacent to the sacrospinous ligament. Clin. Anat., 18(3):200-5, 2005.

Moszkowicz, D.; Peschaud, F.; Bessede, T.; Benoit, G. \& Alsaid, B. Internal anal sphincter parasympathetic-nitrergic and sympathetic-adrenergic innervation: a 3-dimensional morphological and functional analysis. Dis. Colon Rectum, 55(4):473-81, 2012.

Robert, R.; Prat-Pradal, D.; Labat, J. J.; Bensignor, M.; Raoul, S.; Rebai, R. \& Leborgne, J. Anatomic basis of chronic perineal pain: role of the pudendal nerve. Surg. Radiol. Anat., 20(2):93-8, 1998.

Rojas-Gómez, M. F.; Blanco-Dávila, R.; Tobar Roa, V.; Gómez González, A. M.; Ortiz Zableh, A. M. \& Ortiz Azuero, A. Regional anesthesia guided by ultrasound in the pudendal nerve territory. Colomb. J. Anesthesiol., 45(3):200-9, 2017.

Siddiq, M. A.; Khasru, M. R. \& Rasker, J. J. Piriformis syndrome in fibromyalgia: clinical diagnosis and successful treatment. Case Rep. Rheumatol., 2014:893836, 2014.

Vancaillie, T.; Eggermont, J.; Armstrong, G.; Jarvis, S.; Liu, J. \& Beg, N. Response to pudendal nerve block in women with pudendal neuralgia. Pain Med., 13(4):596-603, 2012.

\section{Corresponding author:}

Vasil'ev Yu. L., Associate Professor

Department of Operative Surgery and Topographic Anatomy Sechenov University Moscow

RUSSIA

Email: Dr.vasiliev@gmail.com

Received: 10-07-2019

Accepted: 05-11-2019 